Supplementary Material to:

Functional Dynamics of Human FKBP12

Revealed by Methyl ${ }^{13} \mathrm{C}$ Rotating Frame

\title{
Relaxation Dispersion NMR Spectroscopy
}

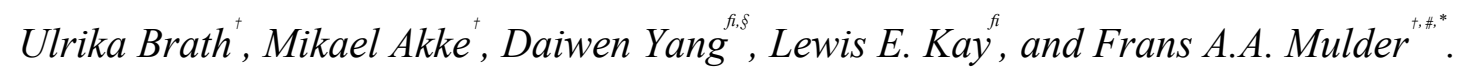




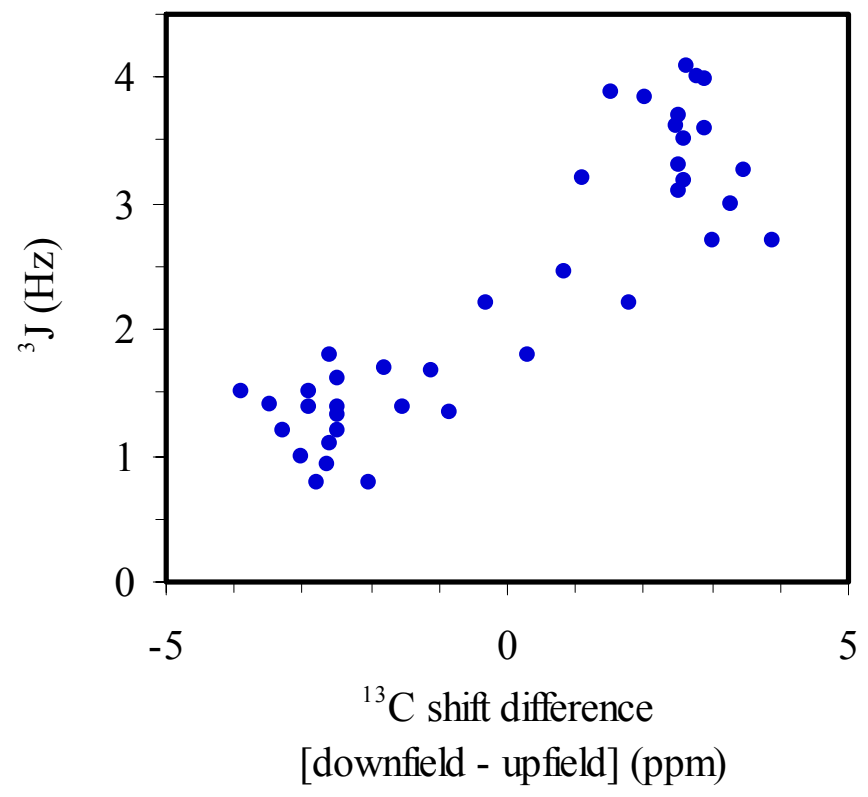

Figure S1 Correlation of ${ }^{3} \mathrm{~J} \delta \delta \mathrm{C} a$ with the methyl ${ }^{13} \mathrm{C}$ chemical shift difference for leucines in a calmodulin/peptide complex [1] and in T4 lysozyme [2].

[1] Bax, A.; Max, D.; Zax, D., Measurement of long-range ${ }^{13} \mathrm{C}-{ }^{13} \mathrm{C} J$ couplings in a $20 \mathrm{kDa}$ protein-peptide complex. J Am Chem Soc 1992, 114, 6923-6925.

[2] Mulder, F. A. A.; Hon, B.; Mittermaier, A.; Dahlquist, F. W.; Kay, L. E., Slow internal dynamics in proteins: application of NMR relaxation dispersion spectroscopy to methyl groups in a cavity mutant of T4 lysozyme. J Am Chem Soc 2002, 124, 1443-1451. 
Figure S2. $R_{2}\left(s^{-1}\right)$ plotted as a function of $\omega_{\text {eff }}\left(0-50000 s^{-1}\right)$.
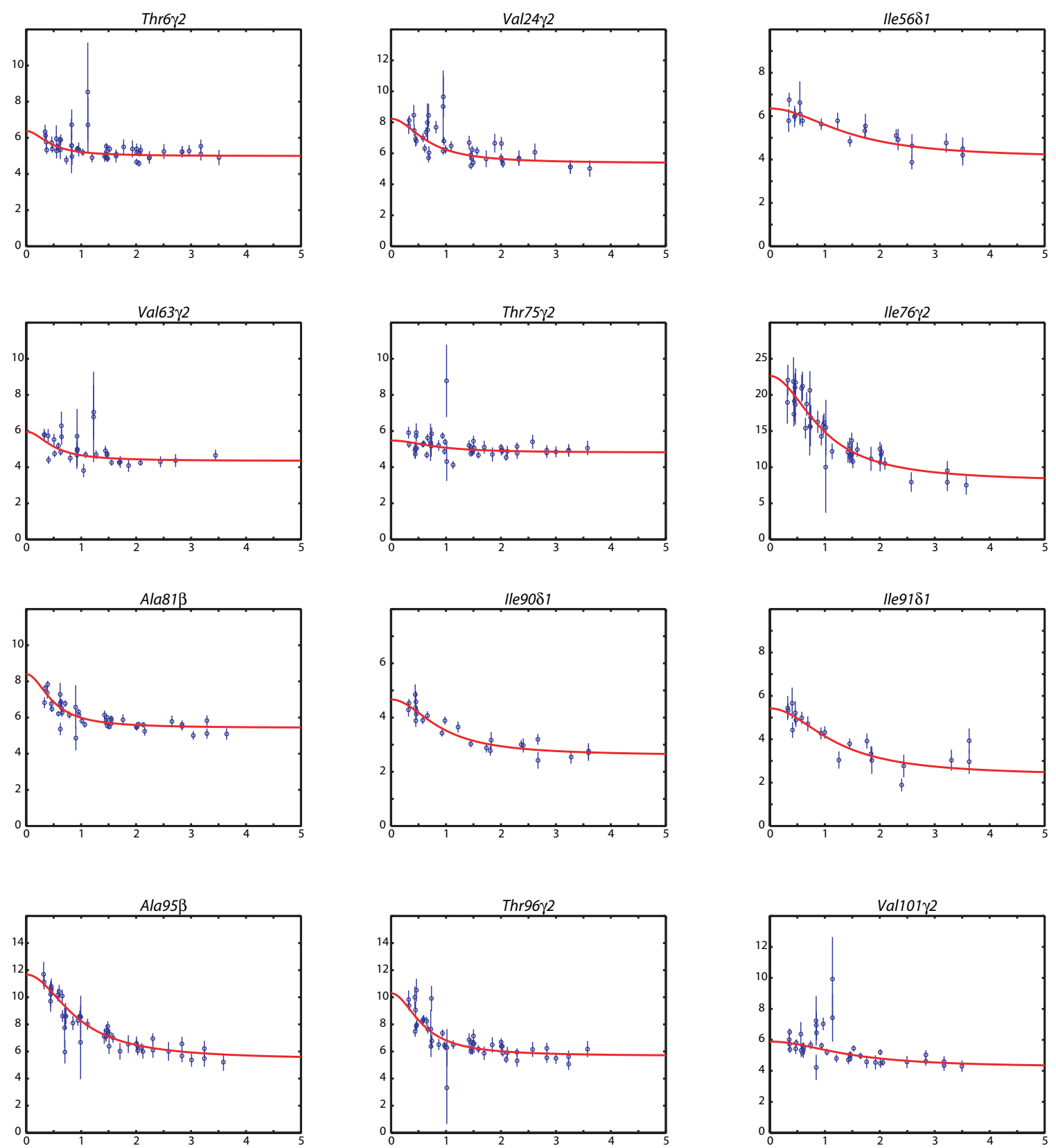

Figure S2 Relaxation dispersion profiles for all methyl groups in FKBP12 that show significant conformational exchange broadening 
Table S1 Offsets and field strengths used in the off-resonance $T_{1 \rho}$ experiment.

\begin{tabular}{|l|l|}
\hline offset, $\mathrm{Hz}$ & $\Omega_{1} / 2 \pi, \mathrm{Hz}$ (repetition) \\
\hline-1500 & 506,520 \\
\hline-1000 & $506,520,921,1475,2311$ \\
\hline-900 & 708,727 \\
\hline-500 & $506,520,921,1475,2311,3189$ \\
\hline 0 & $506,520,708,727,921,1475,2261,2311(2), 3189,3194,4511(2)$ \\
\hline 250 & 921,2311 \\
\hline 500 & $506,520,921,1475,2311,3189$ \\
\hline 700 & 2311 \\
\hline 800 & 2261 \\
\hline 900 & 708,727 \\
\hline 1000 & $506,520,3189$ \\
\hline 1100 & 3194 \\
\hline 1500 & $506,520,2261$ \\
\hline 1600 & 4511 \\
\hline 1800 & 3189,3194 \\
\hline 1900 & 2261 \\
\hline 2000 & 708,727 \\
\hline 2300 & 2261 \\
\hline 2500 & $4511(2)$ \\
\hline 2600 & 3194 \\
\hline 3300 & 3194 \\
\hline 3500 & 4511 \\
\hline 5000 & 4511 \\
\hline & \\
\hline
\end{tabular}

Offsets are defined such that negative values indicate that the carrier was placed upfield from the methyl resonances. 
Table S2 Fitted parameters obtained from the group fit

\begin{tabular}{|c|c|c|c|c|c|}
\hline Residue & $\begin{array}{l}p_{\mathrm{a}} p_{\mathrm{b}} \Delta \omega^{2} \\
\left(10^{3} \mathrm{~s}^{-2}\right)\end{array}$ & $\begin{array}{l}R_{1} \\
\left(\mathrm{~s}^{-1}\right)\end{array}$ & $\begin{array}{l}R_{2,0} \\
\left(\mathrm{~s}^{-1}\right)\end{array}$ & $\chi_{v}{ }^{2}$ & $\begin{array}{l}R_{\mathrm{ex}} \\
\left(\mathrm{s}^{-1}\right)\end{array}$ \\
\hline Thr6 & 7.6 & 2.0 & 4.9 & 1.29 & 1.0 \\
\hline Val24y2 & 21 & 1.3 & 5.2 & 2.40 & 2.7 \\
\hline Ile56 61 & 18 & 0.7 & 4.5 & 1.18 & 2.2 \\
\hline Val63y2 & 10 & 0.8 & 4.2 & 2.09 & 1.3 \\
\hline Thr75y 2 & 5.3 & 1.1 & 4.8 & 1.89 & 0.7 \\
\hline 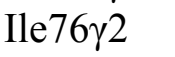 & 124 & 3.7 & 8.6 & 0.96 & 15.6 \\
\hline Ala81 $\beta$ & 18 & 1.7 & 5.2 & 2.66 & 2.3 \\
\hline Ile90 1 & 17 & 0.6 & 2.7 & 1.39 & 2.1 \\
\hline Ile91 $\delta 1$ & 24 & 0.8 & 2.8 & 1.99 & 3.1 \\
\hline Ala95 $\beta$ & 52 & 1.1 & 5.6 & 1.12 & 6.5 \\
\hline Thr96 2 & 31 & 1.5 & 5.4 & 1.93 & 3.9 \\
\hline Val101 2 & 12 & 1.1 & 4.6 & 2.23 & 1.6 \\
\hline
\end{tabular}

